\title{
TEATRO DAS MEMÓRIAS E DOS SABERES: A IMPORTÂNCIA DAS ETNOCIÊNCIAS E DA TROCA ATIVA DE CONHECIMENTOS NOS ECOMUSEUS ${ }^{1}$
}

\author{
Alexandre Fernandes Corrêa* \\ Universidade Federal do Rio de Janeiro - UFRJ \\ alexfcorrea@gmail.com
}

\begin{abstract}
RESUMO: Reflexões a partir de pesquisa sobre o Espaço Ciência do NUPEM/UFRJ Campus Macaé na qual analisamos a aplicação do termo "troca ativa de saberes" usada na criação do projeto de extensão universitária. Ao aprofundarmos o estudo percebemos o uso retórico da expressão, operada sem uma análise epistemológica condizente com sua efetiva aplicação num espaço dialógico. Através do olhar crítico da teoria da Complexidade se compreende a natureza dos obstáculos epistemológicos que entravam a efetiva operacionalização de um conceito dialógico no espaço ainda fixado no paradigma científico clássico.
\end{abstract}

PALAVRAS-CHAVE: Biocultura; Epistemologia; Complexidade; Troca de saberes.

\section{THEATER OF MEMORIES AND KNOWLEDGE: THE IMPORTANCE OF ETHNOCIENCES AND ACTIVE EXCHANGE OF KNOWLEDGE IN ECOMUSEUMS}

\begin{abstract}
Reflections from the research on the Espaço Ciência of NUPEM / UFRJ Macaé in which we analysed the application of the term "active exchange of knowledge" used in the creation of the university extension project. As we deepened the study, we perceive the rhetorical use of expression, operated without an epistemological analysis that is consistent with its effective application in a dialogical space. Through the critical look of the Complexity theory, we understood that the nature of the epistemological obstacles that hinder the effective operationalization of a dialogical concept in the space still fixed in the classical scientific paradigm.
\end{abstract}

1 Texto originalmente elaborado para apresentação no VI CONGRESSO DA ASSOCIAÇÃO PORTUGUESA DE ANTROPOLOGIA: "FUTUROS DISPUTADOS". Universidade de Coimbra, nos dias 2 à 4 de Junho de 2016. Painel T051 - Museus e Democracia Cultural: tensões, diálogos e sentidos.

* Membro da Associação Brasileira de Antropologia (ABA) e da Sociedade Brasileira de Sociologia (SBS). Doutorado em Ciências Sociais PUC/SP. Pós-Doc I em Antropologia UFRJ. Pós-Doc II em Antropologia UERJ. Professor Associado do Campus UFRJ Campus Macaé. Pós-Doc III em Memória Social UNIRIO. 
KEYWORDS: Bioculture; Epistemology; Complexity; Exchange of knowledge.

O Espaço Ciência do NUPEM/UFRJ Campus Macaé foi inaugurado em 2008, durante a Semana Nacional de Ciência e Tecnologia, com a Exposição "Diversidade dos Ecossistemas Costeiros do Norte Fluminense". Está inserido em um contexto de crescimento populacional e expansão econômica pela qual a Região Norte-Fluminense vem passando nos últimos anos desde a instalação da indústria petrolífera nos anos de 1970; causadora de profundas mudanças socioambientais nos municípios costeiros do Estado do Rio de Janeiro.

O Espaço Ciência estabeleceu-se como local de visitação de escolas públicas e privadas $^{2}$ pretendendo conectar os visitantes com a biodiversidade da região, a fim de promover a consciência ambiental e ecológica através de visitas monitoradas nas quais se abordam conhecimentos sobre a diversidade faunística marinha e costeira e aspectos biológicos das espécies representadas na exposição. Tal proposta se sustentaria através de mediações ou "troca ativa" entre os mediadores (ou monitores) e o público visitante, em sua maioria estudantes do ensino básico. Veremos a seguir que tal projeto dialógico não se efetiva plenamente e restringe-se a um único vetor de comunicação (Exposição $\Rightarrow$ Mediador $\Rightarrow$ Visitante).

A exposição permanente é composta por uma tartaruga verde, uma réplica de toninha, um aquário de água doce e diferentes aves e mamíferos terrestres taxidermizados. Os demais exemplares componentes da coleção são empréstimos do Museu Nacional da UFRJ: réplica de tubarão anequim adulto em tamanho natural e uma réplica de esqueleto de golfinho. Assim composta, somente a ala dos mamíferos taxidermizados sofre mudanças a partir a entrada de novos exemplares. A taxidermia dos mamíferos terrestres é resultado do projeto de extensão Educação Científica e Ambiental Através de Uma Exposição Artística dos Mamíferos do Norte-Fluminense, em parceria com a Concessionária Autopista Fluminense, fornecedora dos cadáveres dos animais vitimados por atropelamentos na rodovia BR-101.

2 "O público alvo principal do projeto são alunos e educadores dos ensinos fundamental e médio, que carecem de espaços educacionais desse tipo. A equipe do projeto estabeleceu uma rede de divulgação voltada para as escolas da região, e a partir de 2011 passou a contar com a colaboração da prefeitura de Macaé que disponibiliza o transporte para as escolas públicas. Painéis explicativos e um jogo interativo completam a exposição, que é mediada por Bolsistas de Extensão." Informações fornecidas pela site da UFRJ Campus Macaé / Nupem: http://www.macae.ufrj.br/nupem/index.php/extensao/projetos-em-andamento 
O espaço físico, onde estão expostos os elementos da coleção, é de pequeno porte com planta quadrangular, circundado por paredes de vidro onde se encontram as peças dispostas por toda sua extensão, de tal modo que o visitante tem contato visual com todos os animais apresentados na mesma cena. Durante as visitas, diversos aspectos da biologia e conservação dos organismos são abordados, com monitores demonstrando e indicando pedagogicamente seu funcionamento e classificação. No documento de criação do Projeto sublinha-se a expectativa de que após a experiência vivenciada pelos visitantes, no contato direto com os organismos em exposição, seja estendida "a consciência ecológica para todos os organismos marinhos e ao ecossistema em geral, de modo que a conservação ambiental possa ser entendida como uma atividade naturalmente prazerosa e benéfica para a população." (ESPAÇO CIÊNCIA, 2008)

Desse modo, o objetivo principal definido para a exposição permanente é aproximar o público visitante da fauna local geralmente desconhecida pela população estudantil do Município de Macaé e do Norte-Fluminense. Os visitantes do Espaço Ciência também têm a oportunidade de conhecer a UFRJ Campus Macaé e alguns de seus laboratórios de pesquisa integrada em atividade nos Polos Universitário, da Cidade Universitária, e no Barreto. ${ }^{3}$

Como se vê trata-se de uma exposição de dimensões diminutas mais que possui alcance importante em termos de projeto pedagógico, integrando atividades de extensão, ensino e pesquisa. Possui um fluxo de visitações em torno de mil pessoas por ano, com agendamentos frequentes pelas escolas particulares e públicas do município. Destaca-se que o projeto em tela possui qualidades ao promover os propósitos apresentados no programa divulgado ao público, assim enfatizado: “O objetivo principal desta exposição é fazer com que a população se sinta mais próxima da diversidade biológica, de modo que a consciência ambiental e ecológica possa ser desenvolvida". Todavia, não obstante o reconhecimento desses esforços de divulgação científica, possui questões críticas em relação ao uso do termo "troca ativa de saberes", não explicitado nos documentos expostos no portal, mas que estão inseridos no documento de criação do Projeto de Extensão original (ESPAÇO CIÊNCIA, 2007). Tal termo é inserido seguindo os

3 O Campus UFRJ Macaé possui três polos: Universitário, na Cidade Universitária (Bairro Novo Cavaleiros); Polo Barreto (Bairro São José do Barreto, o qual se encontra o Espaço Ciência e o NUPEM - Núcleo de Pesquisa Ecológicas de Macaé) e o Polo Ajuda (Bairro Ajuda). 
conceitos e diretrizes definidos pela instituição universitária, porém o projeto não operacionaliza plenamente os objetivos epistemológicos pretendidos. Atente-se para o fato que nos documentos referidos contemplando "diretrizes e conceitos" que regem essas ações universitárias extensionistas prevê-se a "interação dialógica", como resultado da ação de um processo de dupla face, qual seja:

A diretriz Interação Dialógica orienta o desenvolvimento de relações entre Universidade e setores sociais marcadas pelo diálogo e troca de saberes, superando-se, assim, o discurso da hegemonia acadêmica e substituindo-o pela ideia de aliança com movimentos, setores e organizações sociais. Não se trata mais de "estender à sociedade o conhecimento acumulado pela Universidade", mas de produzir, em interação com a sociedade, um conhecimento novo. Um conhecimento que contribua para a superação da desigualdade e da exclusão social e para a construção de uma sociedade mais justa, ética e democrática. ${ }^{4}$

Entretanto, não é o que observamos ocorrer no Espaço Ciência objeto dessa pesquisa. Destarte, algumas perguntas emergem desse estudo de caso: Por que não se operacionaliza plenamente esse conceito importante de interação dialógica invocado? Quais são os obstáculos epistemológicos que obliteram a efetivação plena dessa ação extensionista? Qual a natureza e característica das dificuldades teóricas, conceituais e práticas encontradas no projeto em tela?

\section{ESPAÇOS MUSEAIS NA ATUALIDADE}

Antes de responder a estas questões colocadas no texto, procuramos fazer um breve histórico do processo museal até a atualidade, com intuito de balizarmos nossa reflexão tomando um panorama contextualizador como referência crítica. Tal trajeto no ajudará situar nosso olhar interpretativo ao considerarmos as linhas de força que atuam no avanço do discurso museal na atualidade. Nosso objetivo não é exercitar erudição improfícua, mas tentar compreender como que o nosso estudo de caso se conecta a um processo mais amplo em voga na sociedade contemporânea. (FERRÃO, 2017)

4 A Política Nacional de Extensão é pactuada pelas Instituições Públicas de Educação Superior, reunidas no Fórum de Pró-Reitores de Extensão das Instituições Públicas de Educação Superior Brasileiras (FORPROEX), tendo como referência o Plano Nacional de Extensão, publicado em novembro de 1999, o documento Política Nacional de Extensão Universitária, aprovado em maio de 2012, e os seus demais documentos básicos: http://extensao.ufrj.br/index.php/conceitos-ediretrizes 
Como é sabido não existe consenso sobre o surgimento de coleções e museus na civilização ocidental, porém possui certo consenso que o hábito de colecionar objetos remonta da pré-história como testemunham os sítios arqueológicos conhecidos entre nós como sambaquis ${ }^{5}$, assim como a arte rupestre e seus congêneres, parecem indicar uma necessidade de fixar o fluxo do devir em imagens, figuras, registros, etc. Mais próximos de nós, na era da escrita, arqueólogos e historiadores testemunham encontrar-se na Antiguidade coleções de objetos mais refinados e sofisticados, produtos de arte e materiais raros ou preciosos, compondo conjuntos monumentais, pirâmides, obeliscos, objetos variados e acontecimentos memoráveis: memorabilia. Sabe-se também que reunir obras de arte e itens de suposta origem divina, religiosa ou histórica, durante a Idade Média, era visto como uma demonstração de prestígio, distinguindo famílias e grupos aristocráticos expressando seus poderes na ordem do mundo (BITTER, 2009).

Com o advento das grandes navegações e da descoberta do Novo Mundo, a formação de coleções foi muito incrementada originando os primeiros "gabinetes de curiosidades" das aristocracias e realeza, a partir dos quais alguns dos museus europeus mais importantes do século XVIII fincaram origem. Mas foi com as transformações ocorridas após a Revolução Francesa que se viabilizou pela primeira vez o acesso da sociedade civil a estes acervos, agora colocados a serviço da instrução pública. Assim, o museu passa a ser visto como instrumento de educação e cultura propiciando no século XX o surgimento dos primeiros museus temáticos vinculados a universidades e também museus de ciências, técnicas, belas artes e história. Atualmente observamos o auge desse processo culminando no que muitos denominam como sendo a "era dos museus". Período no qual é notório o sucesso desses equipamentos junto ao público, com um crescente número de análises que os consideram espaços dinâmicos e criadores de narrativas culturais múltiplas, capazes de atender a um público diferenciado e especializado (MACDONALD, 1996), ou como no caso de grandes centros, um público multicultural presente em cidades com drástica mudança sócio-econômica-industrial. Pode-se detectar até mesmo um tipo de surto de museomania a se alastrar pelo mundo. Provavelmente como um sintoma da vertigem da aceleração das mudanças

5 Em Portugal designam-se de Concheiros, sendo os mais conhecidos os Concheiros de Muge, nas margens do Rio Tejo, perto da cidade de Santarém. Em língua inglesa, são chamados shell-mounds ("montes de conchas"). Em língua dinamarquesa, são chamados kjökkenmodding. 
socioambientais causadas pelas transformações globais recrudescidas nos últimos dois séculos. (CORRÊA, 2013)

Os museus e centros de ciência têm se multiplicado com grande velocidade no Brasil, especialmente a partir dos anos 1990. Num levantamento realizado pela Associação Brasileira de Centros e Museus de Ciência (ABCMC), em parceria com o Museu da Vida e a Casa da Ciência/ UFRJ, em 2005, identificou-se cerca de 110 dessas organizações - de variados portes e finalidades - distribuídas em todo o país (MASSARANI, 2007). A partir dessa profusão e incremento, tornou-se necessário distinguir e estabelecer critérios para definir museus, espaços museais, centros de ciência e de cultura. Tais definições e parâmetros são explicitados por organizações, nacionais e internacionais, seguindo regras e características que um espaço deve seguir para ser considerado um museu, tentando evitar uma certa deriva promovida pelos excessos nos usos sem critério e parâmetro consensuais.

De acordo com o Estatuto do Conselho Internacional de Museus (ICOM) adotado pela 22 $2^{\mathrm{a}}$ Assembleia Geral, "um museu é uma instituição permanente sem fins lucrativos, a serviço da sociedade e de seu desenvolvimento, aberto ao público, que adquire, conserva, pesquisa, comunica e exibe a herança tangível e intangível da humanidade e seu meio ambiente para propósitos de educação, estudo e entretenimento" (VIENA, 2007). Consideramos que tais características explicitadas nessa definição acarretam no fomento da democratização da cultura, a promoção dos direitos culturais e o desenvolvimento da sociedade bio-centrada.

No Brasil testemunhamos esse esforço de cristalização desaguar na criação do Instituto Brasileiro de Museus (IBRAM) institucionalizado segundo o Decreto-Lei $\mathrm{n}^{\mathrm{o}}$ 11.904 em 14 de janeiro de 2009. A nova autarquia vinculada ao Ministério da Cultura (MinC) sucedeu o Instituto do Patrimônio Histórico e Artístico Nacional (Iphan) nos direitos, deveres e obrigações relacionados aos museus federais. O órgão é responsável pela Política Nacional de Museus (PNM) e pela melhoria dos serviços do setor aumento de visitação e arrecadação dos museus, fomento de políticas de aquisição e preservação de acervos e criação de ações integradas entre os museus brasileiros. Também é responsável pela administração direta de 29 museus (Portal IBRAM, 2016).

Ao incorporar esse novo conjunto de atribuições, os museus agora passariam a influenciar na economia e no bem-estar social de sua localidade. Visando a organização da gestão de seus museus, o Iphan/MinC, com o objetivo de propiciar a eficiência do 
fazer museal resolve, através da Portaria IPHAN no 302 de 7 de julho de 2004, estabelecer parâmetros gerais para a organização da gestão das suas instituições museológicas, colocando o Plano Museológico como a ferramenta principal de planejamento de cada instituição museal, sendo este "indispensável para a identificação da missão e para a definição, o ordenamento e a priorização dos objetivos e das ações de cada uma de suas áreas de funcionamento" (IPHAN, 2006). O Plano Museológico é indispensável para o museu pois este sistematiza o funcionamento e o trabalho interno e externo da instituição na sociedade, além de estabelecer a missão e os programas do mesmo, suas diretrizes e orientações para o desenvolvimento e execução de projetos.

Regulamos nosso olhar para o Plano Museológico pois é nele que reside nossa atenção mais específica, considerando que esta carta constitucional dos espaços museais são de grande importância para a enunciação da ação científica, cultural ou artística pretendida. Por essa razão destacamos do projeto de criação do Espaço Ciência a expressão "troca ativa de saberes", presente no documento de sua fundação. E após termos realizado o trabalho de contextualização, passaremos agora para a análise mais objetiva do plano de ação dialógica pretendida.

\section{O PLANO MUSEAL EM FOCO}

A elaboração do Plano Museológico é baseada no diagnóstico completo da instituição museal, levando em consideração os pontos fortes e fracos, os aspectos das esferas socioculturais, políticas, técnicas, administrativos e econômicos referentes ao papel de atuação do museu. Tal diagnóstico é de cunho participativo e parte fundamental do Plano Museológico, que deve apresentar-se de forma clara e concisa, contando na sua elaboração com a participação direta da equipe da instituição museal e colaboradores externos, e deve estar em conformidade com as diretrizes da Política Nacional de Museus, estabelecida pelo Ministério da Cultura.

O fundamento central do Plano Museológico é criar as possibilidades para que os museus discutam sobre o que são e como pensam inserir-se nas comunidades. A partir de uma sólida definição conceitual de museu, sua finalidade social e seu alcance, as questões de natureza executiva terão maior chance de ocorrerem de maneira mais fluida e efetiva. O museu é parte integrante da sociedade e possui os elementos que lhe 
permitem participar na formação da consciência das comunidades que ele serve e também promover mudanças.

A dimensão criativa do museu reside nas trocas afetivas, no despertar da sensibilidade (Museus $=$ Teatro do sensível), nas intuições e memórias que pulsam, na atualidade da imaginação sonhadora, na espontaneidade das relações (CORRÊA, 2013). Como criar um espaço museal é construir uma espécie de teatro das memórias, os museus ao operarem suas encenações trabalham como quem edita, corta, recorta, cola, mistura, oculta, revela, enfatiza e faz esquecer. O trabalho com a memória implica o reconhecimento do seu caráter seletivo, eletivo e, portanto, político (IBRAM,2013). Nosso ponto aqui é o debate sobre a política da razão científica que se encena no Espaço Ciência em questão.

A partir de pesquisas sobre o Espaço Ciência do NUPEM/UFRJ Macaé analisamos a aplicação do termo "troca ativa de saberes" usada na criação do projeto e na elaboração do seu plano museológico. Ao aprofundarmos as análises percebemos o uso retórico da expressão operada sem uma análise epistemológica condizente com sua efetiva aplicação num espaço museológico potencialmente dialógico.

O entendimento dos museus como espaços de educação é uma percepção relativamente recente na história dessas instituições (MARANDINO, 2008). Paralelo a esta mudança de paradigma dos museus-repositórios para museus como espaços sociais, seguem-se os Espaços de Educação Não-formal, nos quais a designação educação informal abrange todas as possibilidades educativas no decurso da vida do indivíduo, construindo um processo permanente e não organizado. A educação não-formal, embora obedeça também a uma estrutura e a uma organização (distintas, porém das escolares) e possa levar a uma certificação (mesmo que não seja essa a sua finalidade), diverge ainda da educação formal no que respeita a não fixação de tempos e a flexibilidade na adaptação dos conteúdos de aprendizagem a cada grupo concreto. Os museus, quando possuem em sua abordagem, as características de um espaço de educação não-formal, usualmente constituem-se numa instituição educacional autônoma visando o bem cultural, tendo como tipo específico de educação a "educação patrimonial"; como gestão oficial das memórias sociais e naturais (CORRÊA, 2013).

Considerando todos esses aspectos, que aqui só podemos desenvolver rapidamente, contata-se que a educação faz parte de um contexto cultural associado a um processo de desenvolvimento dimensional de aprendizagem, começando pelo 
entendimento que gera a autonomia de raciocínio, continuando pelo processo de julgamento daquilo que é valorizado e culminando no surgimento do afeto pela abordagem utilizada no aprendizado de tal conhecimento. Identificados como espaços de educação não-formal, essa designação busca distingui-los das experiências formais de educação, como aquelas desenvolvidas na escola, e das experiências informais, geralmente atreladas ao âmbito familiar. Entretanto, ainda não há consenso acerca da caracterização e diferenciação dos espaços de educação não-formal.

Apesar do reconhecimento das especificidades educativas que os museus e centros de ciência possuem, diversas vezes os termos "formal", "não-formal" e "informal" são utilizados dubiamente, ou seja, o que alguns consideram como “educação não-formal”, outros denominam como "educação informal” e isso faz com que as definições estejam longe de um consenso. Por exemplo, em língua inglesa usa-se os termos informal science education (educação informal em ciências) e informal sicence learning (aprendizagem informal em ciências) para todo o tipo de educação que pode acontecer em locais como museus de ciência e tecnologia, zoológico, jardins botânicos, no trabalho, em casa, entre outros locais voltados para as ciências (MARANDINO, 2008). Diferentemente das publicações inglesas, em língua portuguesa classifica-se a educação ocorrida fora do ambiente escolar em dois grupos: educação não-formal e educação informal, associando esse último aos ambientes ordinários como trabalho, clube, família, dentre outros. A educação informal pode ser entendida como um tipo de mídia de educação e uma maneira de destrinchar determinados conteúdos programáticos e abordagens que a escola, caracteristicamente um ambiente formal de educação, jamais poderá abordar de modo informal porque ninguém opta pelo o que vai estudar quando frequenta o ensino formal.

A educação não-formal ganhou espaço no panorama internacional em políticas educacionais no final dos anos 1960 (MARANDINO, 2008). Na década de 1960, a educação não-formal focava as necessidades de grupos em desvantagens, possuindo propósitos claramente definidos e organização flexível de métodos, enquanto o sistema de educação formal apresentava vagarosa adaptação às modificações socioeconômicas em curso, exigindo que diferentes setores da sociedade se articulassem para enfrentar as novas demandas da sociedade daquela época. Símbolo desse movimento é o documento da UNESCO de 1972, chamado "Learning to be - The Faure Report", que estabeleceu 
metas acerca da "lifelong education" ou "educação ao longo da vida", e da "learning society" ou "sociedade de aprendizagem".

Central na atividade cotidiana dos museus e centros de ciência é a mediação entre o público e as exposições e atividades oferecidas por essas organizações. A exemplo do que ocorre em outros países, cada museu e centro adota uma filosofia particular, bem como estratégias diferenciadas para a mediação e a capacitação dos mediadores. No entanto, no Brasil, há ainda poucos espaços que permitam compartilhar essas ricas e variadas experiências. Tais espaços permitiriam o estímulo à reflexão sobre o papel da mediação e do mediador, o que poderia levar a um aprimoramento da atividade, bem como a implementação de ações articuladas de capacitação desse profissional (MASSARANI, 2007).

A experiência de aprendizado em um museu, auxiliada pela mediação verdadeiramente promotora da "troca ativa de saberes" -, tem características especificas que a diferenciam da experiência escolar, ao tecer relações entre saberes diferenciados, saberes étnicos e culturais, saberes não-científicos, populares e tradicionais, organizados em uma atividade complexa, no qual não poderia haver hierarquias, mas o respeito pela pluralidade das lógicas classificatórias. E para que essa ligação entre os saberes diferenciados aconteça é preciso que o mediador adapte sua mensagem ao receptor, é esta adaptação só é possível ao buscar entender sobre esse receptor particularmente se há profundas diferenças culturais (étnicas, religiosas, ideológicas, de natureza sócioeconômica, etc., assim como em termos de gênero) - outra grande dificuldade que os mediadores são obrigados a vencer (MASSARANI, 2007). O investimento na capacitação dos mediadores e mudanças no Plano Museológico dos museus afim de modificar suas exposições de modo a contemplar os diversos saberes sobre as ciências naturais, possibilitaria a existência dos etnomuseus e "casas de cultura e ciência", onde esses espaços teriam como objetivo abrigar o passado antes dos processos de urbanização, sejam nos aspectos culturais ou naturais. Tais espaços seriam desenvolvidos através do "conjunto das Ciências Naturais com a História e a Arqueologia, constituindo-se como ancoradouros múltiplos, provindos da matéria da vida vegetal e animal, ou do próprio homem, objetivado pelo passado" (LÉVISTRAUSS, 1976, p. 290-292). Como se verá a seguir, compreendemos que só poderemos ter um alcance pleno desses objetivos se houver a superação da ciência 
clássica e adotarmos os princípios das ciências da complexidade e dos estudos culturais, unindo efetivamente diversas áreas do conhecimento e seus respectivos métodos.

\section{ESPAÇOS MUSEAIS, ETNOCIÊNCIAS E COMPLEXIDADE}

Com o advento das transformações recentes na ordem sociocultural e científica contemporânea, novas abordagens sobre o processo museal surgem no horizonte, como as experiências dos etnomuseus, ecomuseus, museus comunitários, etc. A profusão do fenômeno museológico na atualidade produziu um espectro vasto e variado de experiências museais. Muito embora testemunhemos a manutenção de projetos conservadores e tradicionalistas, no nosso estudo nossa atenção recai sobre as experiências renovadoras e críticas dos modelos convencionais. Tais experimentos museológicos inovadores propõem uma superação da fragmentação e da compartimentação do conhecimento quando se percebe que estão aliados à insurreição de novos saberes submetidos a lógica cultural dominante. De um lado, observamos aliança com os Estudos Culturais ${ }^{6}$ britânicos que desde a década de 1960 provocam questionamentos no cânone da crítica científica e cultural. De outro, detectamos a influência contestadora da Epistemologia da Complexidade, promovendo e invocando a recomposição e a religação dos saberes no campo filosófico e científico (MORIN, 2003), uma sutura do campo epistêmico, reaproximando a Ciência da Cultura.

Os promotores do pensamento complexo em voga, - representado por nomes como Edgar Morin, Ilya Prigogine, Humberto Maturama, Francisco Varela, Isabelle Stengers, etc. - propõem uma nova forma de conceber o mundo reconhecendo, entre outras proposições, a complexidade do real, redimensionada pelos avanços da ciência e tecnologia, exigindo outro modo de articulação do conhecimento, colocando em destaque problemas oriundos dos saberes múltiplos tais como a arte, as humanidades e as ciências (CORRÊEA, 2013).

6 Os Estudos Culturais constituem um campo de investigação de caráter interdisciplinar que analisa as formas de produção, criação e difusão de significados nas sociedades atuais. São um ramo das humanidades surgido no mundo de fala inglesa, desenvolvendo-se mais recentemente nos EUA a partir dos anos 1960, e posteriormente na América Latina e Brasil. Difunde-se atualmente no bojo dos estudos sobre o pós-modernismo, pós-colonialismo, multiculturalismo, e incrementou-se nos movimentos sociais como o dos negros e na segunda voga do feminismo. Um de seus principais autores foi o Stuart Hall, sociólogo de origem jamaicana, que foi diretor do Center for Contemporany Cultural Studies (CCCS), localizado na Universidade de Birmingham. 
A Ciência Clássica avançou modelando sistemas naturais que podem ser descritos com poucas variáveis ou propondo descrições - mas não explicações - para fenômenos mais complexos. Entretanto, este avanço da Ciência (com C maiúsculo) foi gradual até seu triunfo final, de modo que nem sempre este saber ocupou o posto de principal forma de entendimento do Mundo. Como se vê em Wallerstein (2002), o "saber" tem se estruturado há 200 anos dentro de uma recente dicotomia surgida em meados do século XVIII entre filosofia e ciência. Este processo iniciou-se com a substituição da teologia pela filosofia como forma de saber dominante, representando assim a "ocupação do lugar de Deus pelos humanos como fonte de conhecimento primordial", e o saber passa a ser produto do empirismo e do racional, tornando a filosofia uma fonte de especulações. Assim surge uma nova forma de produção de saberes chamada "ciência", e esse conhecimento poderia ser confirmado por qualquer executor da ciência, ou "cientista", pela "simples duplicação das observações empíricas e manipulação dos dados". Consequentemente, a ciência chega ao topo como forma de saber dominante.

Ainda segundo Wallerstein (2002), o status da ciência como "forma de saber vigente" e a "dicotomia ciência e filosofia"-fez-se elucidar a existência de três problemáticas. A primeira reside na premissa de que existem "dois tipos de coisas": o bom e a verdade. Desse modo, a filosofia seria a encarregada de determinar o que era bom e belo, e somente a ciência poderia determinar o que era verdade. Em segundo lugar, a ciência empírica tornou-se antidemocrática, dando direito de ser julgada apenas pelos seus pares. E por último, não houve adesão das pessoas nessa divisão de responsabilidades entre a filosofia e a ciência na busca do bom e do real. E de forma obscura, houve uma reunificação das duas buscas e uma recusa na divisão trimodal do saber entre as ciências naturais, as humanidades e as ciências sociais, motivando o aparecimento dos Estudos da Complexidade, cujo objetivo é atacar o modo vigente de funcionamento da ciência natural baseado na mecânica newtoniana (ou cartesiana), ou seja, aquela que defende a compartimentalização do saber e a fragmentação disciplinar, invocando uma aplicabilidade universal de princípios teóricos questionados atualmente pela própria comunidade dos cientistas naturais (CORRÊA, 2013b). Todavia, os estudos da complexidade não têm por objetivo rejeitar a ciência como fonte de saber, mas sim criticar a ciência baseada na natureza passiva, onde toda a verdade já está inscrita nas estruturas do Universo (WALLERSTEIN, 2002). 
As ciências da complexidade diferenciam da ciência newtoniana, a saber: a) rejeição da possibilidade intrínseca de previsibilidade; b) a normalidade do sistema se afastar do equilíbrio, com suas bifurcações inevitáveis; c) a centralidade da flecha do tempo. No lugar da replicação do evento observado, da estabilidade e equilíbrio, que era a visão da ciência newtoniana, a ciência da complexidade vê instabilidade, evolução e flutuação em toda parte, não apenas na esfera social, mas nos processos fundamentais da esfera natural: a biocultura (CORRÊA, 2008 e 2013a). As ciências da complexidade negam o determinismo e insistem na criatividade em todos os níveis da natureza (PRIGOGINE, 1996), na qual esta última e os humanos não devem estar separados, dessa maneira defendem que a ciência faz parte da cultura, evidenciando a necessidade da reconciliação das Ciências Naturais e das Humanidades no projeto das ciências da Complexidade.

Edgar Morin (2005) é um expoente autor da discussão sobre a ciência mecânica enquanto crítico da ideia clássica fundada na suposição de que a complexidade dos fenômenos podia e devia resolver-se a partir de princípios gerais e imutáveis. Estes princípios, que se revelaram eficientes para o avanço da física newtoniana e da natureza físico-química dos organismos, não são mais suficientes para considerar a complexidade da partícula subatômica, da realidade cósmica e dos progressos da microbiologia. A ciência clássica simplifica os fenômenos e as leis ocultas e imutáveis da natureza. Para o autor, enfrentar a complexidade do real significa confrontar-se com os paradoxos da ordem/desordem, da parte/todo, do singular/geral; incorporar o acaso e o particular como componentes da análise científica e colocar-se diante do tempo e do fenômeno, integrando a natureza singular e evolutiva do mundo à sua natureza acidental e factual (MORIN, 2005).

A reunião das ciências com a filosofia realizada pelas ciências da complexidade causa a emersão da questão acerca das maneiras pelas quais é possível saber e a consequente variedade de saberes, neste caso, sobre o mundo no seu âmbito natural. Edgar Morin, ao refletir sobre os saberes, propõe uma religação dos mesmos, através do investimento firme na "expansão do espaço de diálogo entre as áreas de conhecimento tradicionalmente instituídas, muitas vezes estranhas entre si, oferecendo um espaço intertextual necessário de meditação e reflexão sobre as "consciências do mundo", contribuindo com a superação do abismo que insiste em separar a cultura científica e as humanidades" (SMOLENTZOV, 2003). 


\section{CONSIDERAÇÕES FINAIS}

Museus, Centros e Espaços de Ciência, em sua maioria, não contemplam o conhecimento prévio do visitante acerca do que expõem, ou seja, ignoram a diversidade étnica e cultural. O conhecimento científico produzido nas instituições de pesquisa muitas vezes conflita com o "saber não-científico" criando assim uma relação de subordinação hierarquizada pela qual a Ciência estabelece-se como saber dominante e superior em detrimento dos saberes não-científicos, especialmente a diversidade biológica, em função da falta de estudos etnológicos e antropológicos nesses equipamentos. Em especial as etnociências seriam muito pertinentes para superar essa relação de dominância entre os saberes, pois a mesma define-se como o estudo do conhecimento e das conceituações desenvolvidas por qualquer sociedade a respeito dos conhecimentos tradicionais, populares e das pessoas sobre a vida e a existência e do papel da natureza no sistema de crenças e de adaptação do ser humano a determinados ambientes (POSEY, 1987 e 1996). As etnociências criam assim um sistema cooperativo entre as ciências e o conhecimento tradicional considerado pela ciência como legítimo após um trabalho de superação de seus pressupostos etnocêntricos (COSTA, 2008).

A partir de nossa pesquisa sobre o Espaço Ciência no NUPEM/UFRJ Campus Macaé analisamos a aplicação do termo "troca ativa de saberes" encontrada e aludida na criação do projeto extensionista universitário. Ao aprofundarmos os estudos percebemos o uso retórico da expressão aplicada sem uma análise epistemológica condizente com sua efetiva operacionalização num espaço museal pretensamente dialógico. Caso fosse efetivada uma "troca ativa de saberes" deveríamos ali encontrar a multiplicidade das lógicas classificatórias das diferentes espécies animais e vegetais, incorporando através do diálogo os conhecimentos tradicionais indígenas, das nações tupis litorâneas (Tamoios, Puris e Goytacazes); os saberes dos caipiras e caiçaras; os saberes dos pescadores ainda em atividade na região; etc $^{7}$. A referida "troca ativa" poderia partir do diálogo entre essas lógicas classificatórias diversificadas e em diálogo, promovendo efetivamente a interação dialógica invocada.

7 É curioso que nos programas de pós-graduação da própria instituição já existe considerável número de monografias e dissertações com estudos voltados para a etnobotânica, etnoictiologia, e demais conhecimentos tradicionais. Todavia, negligenciados na concepção do projeto do Espaço Ciência. 
Desenvolvendo estudos sobre a Ciência clássica compreendemos a natureza dos obstáculos epistemológicos ${ }^{8}$ que entravam a efetiva operacionalização de um conceito dialógico nesse espaço museológico. Ao invocarmos a incorporação da Teoria da Complexidade ${ }^{9}$ percebemos a necessidade da sutura da brecha epistemológica que ainda separa a Ciência da Cultura. Assim, vislumbramos um alcance correto das pretensões de exercício de uma democracia cultural que incorpore no espaço museal os saberes tradicionais e não-científicos. A partir de uma reflexão crítica sobre os saberes sujeitados (Foucault, 1999), pela ordem hierarquizante da ciência clássica, surge à cena do teatro das memórias bioculturais as possibilidades de um alargamento da razão (Corrêa, 2008).

As propostas de concepção de ecomuseus estabelecidos em diálogo com as etnociências e outros saberes é um novo caminho para que de fato existam as condições epistemológicas propícias para a efetiva "troca ativa de saberes", propalada no projeto de criação do Espaço Ciência. Todavia, esse empreendimento ainda recebe resistências dos próprios membros da equipe de cientistas, ao obliterar o alcance epistemológico do próprio plano museal proposto. ${ }^{10}$ Observamos através de entrevistas e questionários, a persistência do velho paradigma prejudicando o avanço do "plano extensionista" sugerido nos documentos constituintes do Espaço Ciência. O termo "troca ativa dos saberes" foi usado de forma retórica, invocando uma dimensão epistemológica não refletida e ocultada pelos próprios criadores do projeto. Assim, toda iniciativa verdadeiramente transformadora se vê submetida ainda à hegemonia do paradigma clássico dominante, obliterando o avanço e a superação da ordem simbólica vigente. $\mathrm{O}$ vetor predominante e exaltado na exposição é o velho cânone científico clássico (Exposição $\Rightarrow$ Mediador $\Rightarrow$ Visitante), em que do alto de seu pedestal a Ciência

8 Termo que utilizamos no sentido empregado a partir da obra de Gaston Bachelard, A formação do Espírito Científico, isto é, qualquer elemento ou processo extra/intra científico que, intervindo numa prática científica, oblitera, trava, impede, desvirtua ou produz refração na produção de conhecimentos (BACHELARD, 1996, p. 17-28).

9 Como texto introdutório a crítica efetuada à ciência clássica, nos referimos a obra A Nova Aliança: metamorfose da ciência (PRIGOGINE, 1991). Em síntese, tal crítica consiste na religação de ideias e conceitos da Biologia, da Física, da Termodinâmica e da Cibernética, com intuito de promover uma nova forma de compreensão dos sistemas organizacionais integrados.

10 Foram realizadas doze (12) entrevistas com docentes, discentes e técnicos da UFRJ Campus Macaé envolvidos com Extensão Universitária. Seis (6) foram gravadas em áudio e outras seis (6) respondidas na forma de questionário. A entrevista foi composta por 10 perguntas sobre tipologias de museu, mediações e sobre como o Espaço Ciência NUPEM/UFRJ se insere no contexto da extensão universitária da UFRJ Campus Macaé. 
triunfante soergue-se sobre todos os outros saberes ocultados e silenciados, condenados a subalternidade epistêmica.

Com a aproximação das comemorações do Bicentenário da Independência do Brasil (2022), consideramos oportuno o debate sobre a democracia cultural, pois é cada vez mais importante para o futuro reequilíbrio homeostático da ecologia do planeta, num mundo em erosão biocultural, a recuperação das memórias dos grupos étnicoculturais que foram silenciados pelo cientificismo determinista clássico.

\section{REFERÊNCIAS BIBLIOGRÁFICAS}

BITTER, Daniel; FALCÃO, Andréa; MARANDINO, Martha; MENDONÇA, Rosa Helena. (2009) Museu e Escola: educação formal e não formal. Ano XIX - No 3 Maio.

CORRÊA, Alexandre Fernandes. Patrimônios bioculturais: ensaios de antropologia do patrimônio e das memórias sociais. 1. ed. São Luís: EDUFMA, 2008.

EDUFMA, 2013a

Teatro das memórias: ensaios sobre ação cultural na atualidade. São Luís:

Aproximações entre os Estudos Culturais e da Complexidade na Alta

Modernidade. (2013a) Conferência / I Fórum em Humanidades. Campus UFRJ-Macaé. COSTA, R.G.A. Os Saberes Populares da Etnociência no Ensino das Ciências Naturais. Revista Didática Sistêmica, ISSN 1809-3108, 2008, Volume 8, julho a dezembro.

ESPAÇO CIÊNCIA, 2008. Informações sucintas no site: http://www.macae.ufri.br/index.php/2016-02-19-17-10-55/2016-02-22-13-24-

01/projetos-concluidos/2299-acoes-integradas-do-espaco-ciencia-para-a-promocao-dodesenvolvimento-socioambiental-no-norte-fluminense

ESPAÇO CIÊNCIA cadastrado no ano de 2007, no portal SIGPROJ (MEC/UFRJ): http://sigproj1.mec.gov.br/siex.php?id=7\&plataforma=1\&acao=1

FERRÃO, Victor Alexandre Oliveira Seixas. Os Espaços Museológicos E As Possíveis Mediações Entre Os Saberes Sobre A Diversidade Biológica. Dissertação de Mestrado (Mestrado em Ciências Ambientais e Conservação). Universidade Federal do Rio de Janeiro, 2007, Macaé.

FOUCAULT, Michel. Em Defesa da Sociedade: curso no Collège de France (1975/1976). São Paulo: Martins Fontes, 1999.

IBRAM - Link: http://www.museus.gov.br/

LÉVI-STRAUSS, Claude. Antropologia Estrutural II. Rio de Janeiro: Civilização Brasileira, 1976.

MACDONALD, S.; FYFE, G. Theorizing Museums. Oxford: Blackwell, 1996.

MARANDINO, Martha. A pesquisa educacional e a produção de saberes nos museus de ciência. História, Ciências, Saúde - Manguinhos, v. 12 (suplemento), p. 161-81, 2005. , Martha; MÔNACO, Luciana (Org.) .Educação em Museus: A Mediação Em Foco. São Paulo, SP: Geenf / FEUSP, 2008. 
. Educação em Museus: Pesquisas e Prática. São Paulo: FEUSP,2013.

MASSARANI, Luisa (org.) Diálogos \& ciência: mediação em museus e centros de Ciência. Rio de Janeiro: Museu da Vida/Casa de Oswaldo Cruz/Fiocruz, 2007.

MORIN, Edgar. Religação dos saberes. Rio de Janeiro: Bertrand Brasil, 2003. . (2005) Ciência com consciência. Rio de Janeiro: Bertrand Brasil, 2005

MUSEU E ESCOLA: educação formal e não formal. (2009) Ano XIX - No 3 - Maio. POSEY, Darrel A. Manejo da floresta secundária, capoeiras, campos e cerrados (Kayapó). In: Suma Etnológica Brasileira, volume I: etnobiologia (B. Ribeiro, org.). Petrópolis: Vozes, 1987.

.Ethnobiology and ethnodevelopment: importance of traditional knowledge and traditional peoples. In Pei Shengji, Su Yong-ge, Long Chun-lin, K. Marr \& D. A. Posey (Eds.), 1996.

PRIGOGINE, Ilya \& STENGERS, Isabelle. A nova aliança: metamorfose da ciência. Brasília: Universidade de Brasília,1991.

PRIGOGINE, Ilya. O Fim das Certezas: tempo, caos e as leis da natureza. São Paulo: Editora da Universidade Estadual Paulista, 1996.

SMOLENTZOV, Vera Maria Neves. A Religação das Ciências. Araçatuba, v.2 n.2, p. $69-76 \cdot$ jun, 2004.

WALLERSTEIN, Immanuel. O fim do mundo como o concebemos. Rio de Janeiro: Revan, 2002. 